\title{
Pierre Bourdieu e algumas lições para o Campo da Comunicação ${ }^{1}$
}

\section{Cláudia Lago}

Doutora; Universidade de São Paulo

claudia.lago07@usp.br

\section{Resumo}

O artigo procura relacionar a obra do sociólogo Pierre Bourdieu e seu uso no Campo da Comunicação. Para tanto, parte-se da discussão da gênese das concepções de pesquisa do autor, seguida da apresentação de conceitos fundamentais e recorrentes na Comunicação - como Campo, Habitus e Poder Simbólico - e, por fim, analisa-se as apropriações de parte de sua obra pelo campo da comunicação.

\section{Palavras-chave}

Pierre Bourdieu. Campo da Comunicação. Habitus. Poder Simbólico. Pesquisa.

\section{Introdução}

A obra do sociólogo francês Pierre Bourdieu tem sido objeto de inúmeras incursões por parte de pesquisadores do Campo da Comunicação. A começar, pela própria incorporação dessa ideia a de um "campo da comunicação" que remonta a aspectos fundamentais do arcabouço do autor. Não poderia ser diferente, já que Bourdieu, como lembra Wacquant (2002), é um daqueles intelectuais que, além das descobertas que indicam com sua obra, causam mudanças no modo de pensar e se exprimir dos que estão à sua volta e além. Tal relação prolífica e, até, profunda com a Comunicação, no entanto, nem sempre vem acompanhada de uma reflexão que faça jus aos princípios caros ao autor. Muitas vezes, seus principais contributos, como as noções de campo e habitus, por exemplo, são "usados" descontextualizados de uma matriz teórica pela qual foram gerados e que lhes dá sustentação. Em alguns casos, este uso irrefletido banaliza os conceitos, despindo-os de sua operacionalidade

\footnotetext{
1 Este texto foi produzido a partir as aulas ministradas no Seminário Pierre Bourdieu e o Campo da Comunicação, que ocorreu de 24 a 27 de setembro de 2012 junto ao Programa de Pós-Graduação em Comunicação e Informação da UFRGS.
} 
científica, tornando-os ineficazes para ajudar a compreender os fenômenos sobre os quais se debruçam. Em outros momentos, aspectos primordiais da perspectiva bourdiana, como a relação a ser estabelecida com o ato de pesquisar, são deixados de lado, quando poderiam ser extremamente úteis, se apropriados pela Comunicação.

Com base em tais premissas, este artigo tem como objetivo aprofundar a compreensão sobre aspectos constituintes da vasta obra de Pierre Bourdieu², especialmente, a relação com o ato de pesquisar, um dos baluartes bourdianos. Inicia-se, assim, explorando essa relação, discorrendo sobre conceitos recorrentes nas pesquisas em Comunicação e finalizando com a discussão da apropriação do autor e sua obra pelo Campo, apontando, na sequência, possíveis movimentos de ampliação/adequação/aproveitamento desta relação.

\section{A pesquisa é um esporte de combate}

"A sociologia é um esporte de combate.", é a frase de Bourdieu que define sua relação com o campo sociológico ${ }^{3}$, espaço que, para ele, tem a inegável missão e responsabilidade social de desnudar as estruturas que naturalizam as opressões. Esta perspectiva militante está ancorada em outro aspecto principal de sua obra que, muitas vezes, não é percebido enquanto tal junto à Comunicação, qual seja, a defesa intransigente da racionalidade científica, expressa no conjunto de seus escritos no lugar ocupado pela reflexão sobre a ciência e o ato de pesquisar.

Para Bourdieu a pesquisa, uma atividade racional, científica, é um ofício árduo que requer dedicação, reflexividade e uma atenção profunda e constante aos procedimentos metodológicos. Diante dessa perspectiva ganha especial relevo o trabalho de circunscrição do objeto. Este, por sua vez, só pode ser percebido enquanto uma construção, não está dado, não existe sem essa mediação no espaço social:

\footnotetext{
O que conta, na realidade é a construção do objeto, e a eficácia de um método de pensar nunca se manifesta tão bem como na sua capacidade de constituir objetos socialmente insignificantes em objetos científicos, ou, o que é o mesmo, na sua capacidade de reconstruir cientificamente os grandes objetos socialmente importantes, apreendendo-os de um ângulo imprevisto. (BOURDIEU, 1989, p. 20).
}

\footnotetext{
${ }^{2}$ Foram selecionados alguns textos específicos dentro da imensa produção de Pierre Bourdieu, já que se trata de pensar a relação com o campo da comunicação e não propriamente analisar as contribuições gerais de Pierre Bourdieu.

${ }^{3}$ Este também é o título de um documentário dirigido por Pierre Carle e que tem o sociólogo como objeto. No documentário, acompanhamos Bourdieu em várias atividades: da orientação, às palestras, passando por sua participação em movimentos sociais e sendo entrevistado por rádio comunitária. Entre momentos significativos, identifico aquele em que o sociólogo se ressente da apresentação feita em inglês a americanos, por não poder se expressar na própria língua e, no final, quando combate o antiintelectualismo, presente em falas dentro de movimentos sociais.
} 
A construção do objeto implica uma ruptura com o senso comum, com o préconstruído, com a crença no (que) já (é) sabido, e é um processo extremamente complexo, já que o sociólogo (aqui, acredito que podemos trocar pelo pesquisador da comunicação) é parte do mundo social e está sujeito a esses mesmos condicionantes sociais, os problemas impostos como legítimos e, portanto, valorizados. 0 ato de pesquisar, além de ser um compromisso social, pressupõe o exercício radical da dúvida acerca da própria pesquisa, pois implica ter, como princípio e construção contínua, a reflexão sobre o conjunto do empreendimento científico.

Tal reflexão deve superar a dicotomia entre teoria e metodologia, faces de uma mesma moeda e que são, no entender do autor, indivisíveis. Essa separação, para ele, "[...] constitui em oposição epistemológica uma oposição constitutiva da divisão social do trabalho científico num dado momento." (BOURDIEU, 1989 p. 24), já que toda opção técnica é inseparável das opções “teóricas de construção do objeto" (BOURDIEU, 1989 p. 24).

A perspectiva cumpre-se na obra de Bourdieu em diversos aspectos: seja pela observação e análise de campos os mais distintos, da educação à arte, pela construção de objetos improváveis, como a alta costura, seja pela utilização de métodos e arcabouços de pesquisas os mais diversos, como o uso exaustivo da estatística em obras como A distinção (2007a), ou o uso intensivo de métodos qualitativos, como em A miséria do mundo (1999).

A diversidade metodológica é uma opção coerente com a perspectiva do objeto como construção e vem acompanhada de uma crítica ferrenha ao que chama de "condenações metodológicas". Para Bourdieu, a tendência de alguns pesquisadores desdenharem determinados métodos, justamente aqueles com os quais não se identificam, nada mais é do que uma forma de "[...] tornar a necessidade em virtude, de fingir que se ignora (no sentido ativo) o que, muito simplesmente se ignora." (BOURDIEU, 1989 p. 25). Da mesma forma, utilizar-se de forma intensiva e exclusiva de um mesmo método, para o autor, é apenas a indicação de que se está amarrado (ou seria aprisionado?) a uma tradição exclusiva e exclusivista.

A liberdade extrema dentro da pesquisa, com o uso dos métodos e técnicas que se julgarem necessários, não pode se confundir com a falta de rigor. Ao contrário, a liberdade deve ser relacionada a uma reflexividade e vigilância atenta à utilização das técnicas para garantir o rigor científico. Cabe, aqui, novamente, ressaltar que a pesquisa é um empreendimento científico e que "[...] a reflexividade obsessiva, que é a condição de uma prática científica rigorosa, nada tem de comum com o falso radicalismo das discussões acerca da ciência que actualmente se multiplicam." (BOURDIEU, 1989, p. 42-43). 
Aqui aponto para uma contribuição que poderíamos incorporar mais solidamente a nosso campo. Qual seja, a necessidade de ampliar o uso de outros métodos que fogem à alçada da perspectiva qualitativa, estes com certeza proeminentes em nossas pesquisas.

Em trabalho anterior (LAGO, 2011) indicava tal quadro em relação às pesquisas sobre Jornalismo e apontava para possíveis causas. Desde então, baseada em minha experiência como parecerista, tanto de periódicos quanto de congressos, percebo que a lacuna persiste. Continuamos a construir nossas percepções sobre a Comunicação sem que lancemos mão de dados oriundos de pesquisas quantitativas ou, mesmo, que utilizemos dados e índices que já estão presentes e disponíveis, apesar de dispersos em várias bases ${ }^{4}$, o que faz com que às vezes incorramos no erro de produzir conclusões generalizantes sobre universos que, na verdade, não conhecemos realmente.

A perspectiva de Bourdieu é produto de uma inserção singular no universo acadêmico, fruto de uma trajetória que, como enfatiza Wacquant (2002), chocou-se com suas próprias previsões de sucesso direcionado àqueles "eleitos" de antemão pelas posições ocupadas. Bourdieu, ao contrário da maioria dos intelectuais reconhecidos de seu tempo, era filho de agricultores, originário de um espaço periférico, e foi esse não pertencimento à casta dos escolhidos que, segundo ele, originou um habitus laminado, cindido, não plenamente adequado ao universo acadêmico (BOURDIEU, 2006) e que o tornou propenso a desconfiar das regras naturalizadas, especialmente, às postas para aquele universo. É este lugar no espaço que o coloca frente a um campo acadêmico, nos anos 50, dominado por Sartre e a ideia do intelectual total e livre, um campo em que a Filosofia ocupava o mais legítimo dos espaços, distinguindo-se dos métodos e objetos das ciências sociais, configurando-se a partir de um isolamento escolástico e intelectualista, alicerçado em um grupo socialmente homogêneo (idem). A esta experiência inicial, soma-se outra extremamente importante, que irá marcar sua produção, qual seja, o trabalho de campo na Argélia, que o confrontou com a necessidade de tomada de posição dos intelectuais ao mesmo tempo em que incorporou a reflexividade da prática como forma de enfrentar as duras condições da pesquisa. Como o próprio autor identifica5:

\footnotetext{
${ }^{4}$ Obviamente que a experiência como parecerista serve apenas como ponto de partida para a identificação de lacunas. E que existem exceções, como a pesquisa coordenada por Jacques Mick e Samuel Lima (2013) sobre o perfil do jornalista brasileiro.

${ }^{5}$ Tradução minha de: "Solo se puede sobrevivir, en sentido propio, en semejante situación [...], a costa de una reflexividad permanente y práctica que resulta imprescindible, en las condiciones de urgencia y de peligro extremos, para interpretar y valorar instantáneamente la situación y movilizar, más o menos conscientemente, los conocimentos y habilidades adquiridos en la experiencia social previa. (La vigilancia critica que introduje en mis investigaciones posteriores procede, sin duda, de estas primeras experiencias de la investigación realizadas en unas conditiones en las que nunca se da nada por sentado y todo se replantea y cuestiona constantemente [...]." (BOURDIEU, 2006, p. 74-75).
} 
Só se pode sobreviver, em sentido próprio, em semelhante situação [...] à custa de uma reflexividade permanente e prática que resulta imprescindível, em situações de urgência e perigo extremos, para interpretar e valorizar instantaneamente a situação e mobilizar, mais ou menos conscientemente os conhecimentos e habilidades adquiridos na experiência social prévia. [...] A vigilância crítica que introduzi em minhas investigações posteriores provêm, sem dúvida, destas primeiras experiências de investigação, realizadas em condições tais que nunca se dá nada por garantido e tudo se redefine e questiona constantemente. (BOURDIEU, 2006, p. 74-75).

É ainda como fruto de seu trabalho enquanto etnólogo na Argélia, que se consolida a perspectiva da pesquisa como esforço coletivo e não empreendimento individual, marca registrada de suas pesquisas, escritos e reflexões.

Aqui cabe mais um adendo apontando contribuições possíveis de Bourdieu à Comunicação enquanto campo de pesquisa. Mesmo que as definições deste campo não se limitem a uma circunscrição do objeto (ademais já sabemos que esta deverá ser sempre produto de uma construção teórico-metodológica), a pesquisa em comunicação passa pela percepção da comunicação enquanto fenômeno. E a comunicação como objeto obriga a um olhar multidisciplinar, ou quando menos, a um entrecruzamento entre vários olhares possíveis. Ora, este empreendimento só poderá ser feito de forma coletiva e pressupõe um profundo trabalho de resgate do conhecimento já produzido 6 , perspectiva que, parece-me, ainda temos de fazer avançar.

A reflexividade e a pesquisa enquanto empreendimento coletivo inserem-se em outras premissas, também, muitas vezes, deixadas de lado em nossas apropriações do universo bourdiano e que dizem respeito à necessidade de "objetivar" - aqui, no sentido de dar a conhecer, tornar objetivo, o conhecimento sobre o mundo, papel da ciência social7.

A primeira etapa de tal objetivação passa por dar a conhecer, objetivar o chamado senso prático, separando-o das explicações científicas. Este procedimento é necessário para que a ciência social não seja tomada como, apenas, mais um dos pontos de vista sobre o mundo, como tantos outros,

[...] mas para subtrair a razão científica à razão prática, para impedir que esta chegue a contaminar aquela, para evitar que se trate como instrumento de conhecimento aquilo que deveria ser objecto de conhecimento, quer dizer, tudo o que faz o sentido prático do mundo

\footnotetext{
${ }^{6}$ Novamente, aqui, uma impressão (se pensarmos em termos bourdianos, uma heresia): somos um campo que pouco reflete e se apropria do que existe. A quantidade de artigos submetidos a periódicos que não cita artigos correlatos publicados nos próprios periódicos a que se submetem pode ser um indicativo disso. E a exiguidade de pesquisas em rede, essencialmente coletivas, também.

${ }^{7}$ Bourdieu refere-se geralmente à Sociologia, mas creio que podemos incluir, aí, nossos estudos em Comunicação, em que pesem as diferenças epistemológicas e estatutárias dessas campos de pesquisa.
} 
social, os pressupostos, os esquemas de percepção e de compreensão. (BOURDIEU, 1989, p. 43).

0 trabalho de objetivação, que poderíamos resumir aludindo à tão comentada (e, talvez, nem tão efetivada) ruptura epistemológica, implica um rompimrnto com tudo o que é preconcepção, o que significa abdicar dos sistemas de classificação que se tem em nome da construção de outros na relação com o objeto. Reconhecer as nossas próprias características, motivações, esquemas de percepção, como forma de tentar atuar, sempre limitadamente, sobre elas. Ação que se completa, ou se efetiva, por meio do empreendimento coletivo de pesquisa, que permite o diálogo e o exercício mais eficaz de descrença nos pressupostos assumidos como verdades ou "fatos".

A tarefa pode afastar o perigo de tomar como certo o que diz a doxa, a crença comum, seja ela a doxa do senso comum, seja ela a ou a doxa douta, que "[...] atribui o nome de ciência a uma simples transcrição do discurso do senso comum." (BOURDIEU, 1989, p. 44). A pedagogia da pesquisa, o ato de ensinar/aprender a pesquisar, ao mesmo tempo em que deve transmitir os "instrumentos de construção da realidade", deve "[...] produzir uma formidável atitude crítica, uma tendência para por em causa esses instrumentos." (BOURDIEU, 1989, p. 44-45).

Esta compreensão, ao mesmo tempo em que prega a possibilidade e a necessidade de se trabalhar com vistas à construção de um conhecimento propriamente científico, também evidencia as dificuldades inerentes à ação:

O sonho positivista de uma perfeita inocência epistemológica oculta na verdade que a diferença não é entre a ciência que realiza uma construção e aquela que não a faz, mas aquela que o faz sem o saber e aquela que, sabendo, se esforça para conhecer e dominar o mais completamente possível seus atos, inevitáveis, e os efeitos que eles produzem, também inevitavelmente. (BOURDIEU, 1999, p. 694-695).

Aqui, novamente tergiverso em direção às possíveis lições em relação à Comunicação. Acredito que nosso campo é marcado pela capacidade discursiva dos agentes envolvidos com a produção de bens simbólicos. Isso, além da dificuldade de objetivarmos, enquanto pesquisadores, nossa relação com os objetos construídos, “(...) condição de ruptura com a propensão para investir no objeto, que está sem dúvida na origem de seu interesse pelo objeto." (BOURDIEU, 1989, p. 45), faz com que enfrentemos, muitas vezes, uma reação à objetivação, por parte dos sujeitos da pesquisa que, “[...] jogando com sua proximidade social com o pesquisador, tentam [...] se proteger, prestando-se aparentemente ao jogo e tentando impor, sem o saber sempre, uma aparência de autoanálise." (BOURDIEU, 1999, p. 702). 
Essa reação, se não percebida e combatida pelo pesquisador, acabará por reforçar o senso comum do campo da comunicação à Comunicação como empreendimento científico. Para Bourdieu, os agentes sociais não tem, necessariamente, acesso aos motivos das suas ações/descontentamentos e o trabalho sociológico (científico) deve ser realizado a partir dos moldes socráticos, da maiêutica, já que deve ajudar a revelar aquilo que os agentes, conhecendo, não conhecem. 0 pesquisador deve ter uma disposição de "[...] perseguir a verdade do entrevistado [...]" (BOURDIEU, 1999, p. 708) ${ }^{8}$.

\section{Conceitos operativos}

É somente dentro desse arcabouço, de uma proposta científica militante e da defesa da racionalidade, que as noções de habitus e campo podem ser entendidas em toda sua amplitude. Estas noções fundam-se em um projeto rigoroso e ambicioso, que busca responder à questão recorrente da sociologia sobre a relação sujeito x sociedade, sem abrir mão da Racionalidade e da Ciência e da possibilidade (e dever) da sociologia enquanto instrumento de explicação sobre os mecanismos sociais. A proposta de Bourdieu dialoga com a filosofia, ancora-se nos cânones da Sociologia e se contamina da Antropologia. Nesse movimento, o autor resgata tanto a Fenomenologia e o sujeito, quanto o Estruturalismo, ao qual acrescenta o componente histórico. Se percebemos em seus escritos, o Estruturalismo de Lévi-Strauss como legitimador da Ciência Social e o projeto de construção da Sociologia, como em Durkheim, também veremos a centralidade da questão com o poder e a dominação (herança marxista) e a relação do sujeito com as estruturas sociais (aos moldes weberianos).

A reintrodução do sujeito na estrutura, feita por Bourdieu, escapa da armadilha estruturalista de resumir o mesmo a um epifenômeno da estrutura e, ao mesmo tempo, da armadilha fenomenológica de dotá-lo de um livre arbítrio constante. 0 sujeito, não mais um indivíduo, passa a ser um "agente" vivendo no campo dos possíveis, investindo os princípios de seu habitus gerador na ação. O habitus é a forma de "Sair da filosofia da consciência sem anular o agente na sua verdade de operador prático de construção do objeto" (BOURDIEU, 1989 , p. 62) 9 .

\footnotetext{
${ }^{8}$ Já que muitas de nossas pesquisas optam pelo método da entrevista com sujeitos, cumpre notar que Bourdieu (1999), discorrendo sobre o tema, alerta para condições de realização de entrevista, que passam por uma efetiva comunicação entre os envolvidos, estabelecendo proximidade, trocas, familiaridades, estratégias de escuta, respeito pela fala e abandono da neutralidade em nome da construção realista e também, inúmeras vezes esquecido por nós, a questão política e ética inerente à publicação da entrevista posteriormente.

${ }^{9}$ Cabe relembrar o conceito de habitus: "[...] sistemas de disposições duráveis, estruturas estruturadas predispostas a funcionar como estruturas estruturantes, isto é, como princípio que gera e estrutura as práticas e as representações que podem ser objetivamente
} 
Conforme ressaltado anteriormente (LAGO, 2014), o habitus não faz sumir o indivíduo dentro da estrutura social, já que o conjunto de suas disposições, que o predispõem para a ação, é interiorizado e exteriorizado em um movimento dialético durante toda sua vida, a partir de posições "herdadas" de classe, gênero, etc, e, também, pelo confronto com outros indivíduos e agentes. Mas, ao mesmo tempo, “[...] relembra a cada momento que a estrutura social está inscrita neste sujeito - em seu modo de pensamento, em suas percepções e gostos, em suas escolhas e ações, em seus interesses e desinteresses, em seu corpo." (LAGO, 2014, p. 217). Assim, o habitus não diz respeito apenas à interiorização das normas e valores sociais, das ideologias, dos códigos de conduta, das ações "boas" ou "ruins", do comportamento que é "correto" ou "incorreto". Ao operar como um sistema classificatório, ele orienta nossa forma de ver, entender, perceber o mundo e mesmo de identificar o real. Estes esquemas gerativos, apesar de interiorizados subjetivamente, o são também de forma coletiva, o que explica a homogeneidade dos habitus subjetivos, de indivíduos, conforme seus espaços sociais.

Atrelado ao conceito de habitus surge o de campo, uma "Estenografia conceitual de um modo de construção do objeto que vai comandar - ou orientar - todas as opções práticas da pesquisa." (BOURDIEU, 1989, p. 27). O campo, assim, é o espaço construído pelo pesquisador, que permitirá pensar os espaços sociais como relacionais, outra perspectiva caríssima ao autor e que, muitas vezes, negligenciamos. 0 campo só existe enquanto construção na pesquisa e ele pode assegurar que não se pense o mundo social como uma realidade dada, já posta. A noção de campo, portanto, é inseparável da pesquisa empírica e tem uma função epistemológica que se liga à construção do objeto de pesquisa.

Segundo Bourdieu, o campo surge de uma recusa às alternativas no ato de compreender os fenômenos: ou submeter-se a uma formalização interna ou reduzi-los às demandas externas, e significa pensar em um "[...] campo de produção como espaço social de relações objetivas [...]" (BOURDIEU, 1989, p. 64).

Dessa formulação, derivam-se as características dos campos, definidos como espaços de lutas concorrenciais em que os agentes, munidos de diversos quantun de capital, disputam o direito à legitimidade: não apenas o de "falar" no campo, mas, principalmente, o de determinar o que é legítimo ser falado. 0 capital específico do campo é o que está em jogo e,

\footnotetext{
'regulamentadas' e 'reguladas' sem que por isso sejam o produto da obediência às regras, objetivamente adaptadas a um fim, sem que se tenha necessidade da projeção consciente desse fim ou do domínio das operações para atingi-lo, mas sendo, ao mesmo tempo, coletivamente orquestradas sem serem o produto da ação organizadora de um maestro." (BOURDIEU, 2007b, p. 86, tradução nossa).
} 
ao mesmo tempo, a moeda que dá poder ao jogador. A partida de jogo pressupõe jogadores dotados de um habitus que implica o reconhecimento das regras e dos instrumentos de disputa.

É a noção de campo que organiza a análise relacional e incorpora elementos da teoria econômica, que são ressignificados, como o de "capital" a moeda de troca e o objeto de procura dos campos. Cada campo tem, como totem, um capital específico, que é distribuído de forma desigual entre os jogadores. Existem vários tipos de capital: social, cultural, econômico, simbólico. A importância destes depende do tipo de campo e do seu momento. No campo intelectual, por exemplo, a moeda é o capital cultural, assim como, no campo econômico, é o capital econômico. Mas as relações se organizam, inicialmente, em torno da posse maior do capital global, seguido da distribuição de capital específico (LAGO, 2014).

Os campos têm uma autonomia, que é sempre relativa, pois, como são espaços relacionais, estão sempre em confronto/contato com outros espaços que ameaçam esta autonomia - especialmente, o campo econômico, com a capacidade de influir diretamente na autonomia dos demais espaços. A autonomia é alcançada quando os campos, em um processo histórico, libertam-se, relativamente, das demandas externas e passam a existir em função das regras internas. Nesse processo, algumas invariabilidades aparecem, como o surgimento de consumidores que permitem a manutenção do corpo de especialistas do campo - estes, propensos a aceitar, como legítimas, apenas as determinações inerentes ao próprio espaço de produção, que são vistas como "naturais" e as únicas possíveis; e a consolidação das instâncias de legitimação, consagração e difusão que, por sua vez, atuarão para determinar a partir dos valores e percepções internos ao campo o que é considerado adequado, legítimo, etc.

A distribuição desigual de capital específico do campo resulta em uma separação entre os agentes ortodoxos, aqueles que possuem mais capital, e os heterodoxos, os que possuem menos capital, que se traduz em lutas entre os que querem manter sua posição e os que lutam para desacreditar essas posições, imprimindo nova concepção de legitimidade. 0 campo, portanto, não é um espaço homogêneo, ao contrário. Dentro desses loci existe uma luta perene para garantir e/ou subverter os espaços e posições ocupadas pelos agentes em confronto. 0 que está em jogo, sempre, é: 
[...] a conservação ou a subversão da estrutura de distribuição do capital específico [em uma disputa que] [...] pressupõe um acordo entre os antagonistas sobre o que merece ser disputado, fato escondido por detrás da aparência do óbvio, deixada em estado de doxa, ou seja, tudo aquilo que constitui o próprio campo [...]. (BOURDIEU, 1983, p. 90).

É o recurso à noção de campo, necessariamente empírica, que atua como uma forma de resistir à tentação de esquecer que nossa relação com o mundo social é uma construção. Tal esquecimento compromete todo o projeto científico e se dá, por exemplo, ao assumirmos "[...] a diferenciação social como forma de grupos definidos como populações, através da noção de classe [...] (em vez de) pensá-la como forma de um espaço de relações." (BOURDIEU, 1989, p. 28).

Além disso, pensar o real como relacional implica uma desconstrução do que, aparentemente, sabemos: "Se é verdade que o real é relacional, pode acontecer que eu nada saiba de uma instituição acerca da qual eu julgo saber tudo, porque ela nada é fora das suas relações com o todo." (BOURDIEU, 1989, p. 31). Esta, a meu ver, é uma das grandes contribuições do pesquisador que a área poderia assumir: a de exercer uma vigilância epistêmica sobre seus objetos, que tradicionalmente impõem-se ao nosso olhar, que tendemos a perceber enquanto familiares, e que, muitas vezes, temos a impressão de "conhecer", já que estamos imersos, cotidianamente, no universo comunicacional.

Essa perspectiva é interessante se pensarmos, por exemplo, no conceito de classe social, que, para Bourdieu, é percebido de forma diferente do proposto pelo marxismo linear. As classes não são coisas dadas, mas construídas e pensadas dentro do espaço de relações que são os campos sociais, onde agentes distintos ocupam posições distintas - não estão todos no mesmo lugar com as mesmas disposições práticas, mesmo que compartilhem o locus dos dominantes, ou dos dominados.

Nesses espaços, as ações sociais realizadas pelos indivíduos, dotados de disposições constituídas em suas histórias de vida (agentes investidos de seus habitus), encaminham-os para determinadas possibilidades, objetivamente, inscritas no mundo social. Bourdieu explica fazendo uso do dito: "as uvas estão verdes", quer dizer: "[...] eu sou tentado a investir naquilo em que posso e da forma como posso. E, dependendo de meu lugar na estrutura, muitas vezes eu não tenho escolhas possíveis [...]".

Tal constatação alarmante, agregada a pesquisas que originaram suas primeiras obras, onde Bourdieu desnuda os esquemas de reprodução estruturais e, pior, denuncia a falácia do mérito individual dentro dos espaços consagrados, como a escola, lhe renderam a 
alcunha de ser o filósofo da reprodução. Na verdade, avalio que é o oposto disso e o habitus, responsável pela desmistificação da meritocracia, só pode ser pensado enquanto reprodutivista quando as críticas:

[...] fazem de um conceito contingente - modificável por práticas diversas e, sobretudo, por percepções potencialmente incoerentes com as oficiais uma ferramenta ancorada na necessidade e na reprodução. Os que acusam esse estruturalismo genético e histórico de imobilismo possivelmente resistem ao imenso poder das regularidades sociais. (ELBAUM; HALPERN, 1998, p. 56).

Outro importante conceito que podemos depreender a obra o autor é o de Poder Simbólico:

[...] como poder de constituir o dado pela enunciação, de fazer ver e fazer crer, de confirmar ou de transformar a visão do mundo e, deste modo, a aç̧ão sobre o mundo, portanto o mundo; poder quase mágico que permite obter o equivalente daquilo que é obtido pela força (física ou económica), graças ao efeito específico de mobilização, só se exerce se for reconhecido, quer dizer, ignorado como arbitrário. (BOURDIEU, 1989, p. 14, grifo do autor).

Essa noção, facilmente compreensível, tem sido largamente utilizada nos estudos em Comunicação, já que aponta para uma dominação que se dá por meio da cultura e dos aparatos de produção de bens simbólicos, essenciais para garantir que a dominação seja reconhecida como legítima, atuando para que se imponha, sem que se perceba, as significações que se coadunam com os interesses dos dominantes.

Novamente é necessário ressaltar que, se pensarmos em todo o espectro bourdiano, o poder simbólico não existe enquanto dado, deve ser apreendido a partir da vivência empírica de pesquisa, e não é produto de uma orquestração linear e consciente dos chamados "dominantes", como muitos das nossas pesquisas inferem a partir do conceito. Ao contrário, é parte de uma orquestração sem maestro, o que o torna muito mais complexo e eficaz.

\section{Relação com a Comunicação}

Podemos pensar a relação da obra de Pierre Bourdieu com a Comunicação a partir de dois caminhos principais. 0 primeiro, enfocando aspectos de sua produção que trataram diretamente de nosso campo ou que foram entendidos pelo campo da Comunicação como dizendo respeito a ele, analisando algumas das apreensões possíveis. 0 segundo é perceber, em nossa produção, como são ressignificados os conceitos e noções do autor. Este segundo caminho, apesar de bastante instigante, exige um esforço de pesquisa que não cabe agora 
empreender. Mesmo o primeiro caminho, para efeitos deste artigo, tem que ser reduzido, selecionando no amplo universo do autor, alguns textos/obras que são frequentemente citados e incorporados pela Comunicação.

Para tanto, seleciono, entre vários, para este exercício, o texto Sobre a televisão (1997), a despeito da importância e proeminência de textos como a Economia das Trocas Simbólicas (1987). Essa escolha se deve pelo fato do texto corresponder a uma das obras mais veiculada entre nós, especialmente, nos anos posteriores à sua tradução para o Português, inclusive, por conter o texto A influência do Jornalismo, em que Bourdieu traça elementos para uma construção do jornalismo enquanto campo.

Apesar de conter boa parte dos princípios detalhados em outras obras, Sobre a televisão é um texto programático, apresentado em cursos do Collège de France e difundidos em 1996 pela Paris Première. Como outros textos do autor, é uma "carta programa", que causou um furor enorme nos meios televisivos e fora deles, principalmente, porque, nele, Bourdieu lança sua crítica aos produtores de bens simbólicos por excelência e à TV, a qual considerava um pernicioso propagador do polo comercial entre outros campos de produção simbólica.

Este texto, muitas vezes citado, quase nunca o é dentro de seus limites. E, especialmente na França, causou um mal estar e uma avalanche de críticas por parte dos veículos e jornalistas que se sentiram ameaçados a despeito das próprias previsões do autor:

\begin{abstract}
Posso desejar, mas sem ter muitas ilusões, que minhas análises não sejam recebidas como 'ataques' contra os jornalistas e contra a televisão, inspirados por não sei que nostalgia passadista de uma televisão cultural estilo Tevê Sorbonne ou por uma recusa, igualmente reativa e regressiva, de tudo o que a televisão, a despeito de tudo, pode proporcionar através, por exemplo, de certos programas de reportagem. Embora eu tenha todas as razões para temer que elas sirvam sobretudo para alimentar apenas a complacência narcísica de um mundo jornalístico muito propenso a lançar sobre si próprio um olhar falsamente crítico, espero que possam contribuir para dar ferramentas ou armas a todos aqueles que, enquanto profissionais da imagem, lutam para que o que poderia ter se tornado um extraordinário instrumento de democracia direta não se converta em instrumento de opressão simbólica. (BOURDIEU, 1997, p. 13).
\end{abstract}

O objetivo do texto não é uma crítica pura e simples à televisão, mas sim à influência que ela passa a exercer nos campos de produção cultural ao instigar nestes suas próprias noções, seus valores, sua forma de percepção e, principalmente, exposição.

O intento do autor parece ser apontar para o fato de que agentes de outros campos, ao se relacionarem com a TV, perdem sua possibilidade de falar em seus próprios termos, a 
partir das regras de seus próprios campos, propagando uma perspectiva narcísica:

[...] ao aceitar participar sem se preocupar em saber se se poderá dizer alguma coisa, revela-se muito claramente que não se está ali para dizer alguma coisa, mas por razões bem outras, sobretudo para se fazer ver e ser visto. (BOURDIEU, 1997, p. 16).

E por que isso deve causar tanto mal estar? Dentro da perspectiva bourdiana, porque cientistas e pesquisadores têm uma missão: devem devolver à sociedade o desnudamento das estruturas que constatam por meio de seu ofício. E esta devolutiva fica comprometida se subsumida aos imperativos da TV. Dentro da perspectiva militante, Bourdieu propõe aos intelectuais um projeto coletivo contra a instrumentalização da TV, o qual implica em não deixar de ir à TV, ao contrário, mas em produzir para a própria TV, em lutar dentro desta para estabelecer condições distintas de fala, nunca ignorando as regras daquele campo, suas lógicas internas e sua especificidade ${ }^{10}$.

Partindo dessa constatação, Bourdieu inicia um desnudamento das regras dentro daquele universo. 0 autor indica que a TV opera uma imposição visível do assunto a ser tratado, das condições de comunicação do que será tratado e do tempo em que o fará, que não é o tempo necessário para a exposição da reflexão.

Tudo isso se dá em um espaço, a divulgação televisiva, que age como um "árbitro de acesso à existência social e política", com um imenso poder de estabelecer efeito do real e de mobilizar construções sociais (BOURDIEU, 1997, p. 29) e que atua a partir da lógica do mercado, buscando o espetacular e o inusitado, reforçando a urgência em detrimento da reflexão, e a dramatização como forma de acessar os conflitos.

A respeito da urgência versus a reflexão, o autor aponta para a exiguidade e raridade do tempo televisivo e que, "[...] se minutos tão preciosos são empregados para dizer coisas fúteis, é que essas coisas tão fúteis são de fato muito importantes na medida em que ocultam coisas preciosas." (BOURDIEU, 1997, p. 23). Por outro lado, a urgência acontece em detrimento do pensamento, já que, para o autor, há uma relação entre pensar, no sentido de refletir, e o tempo. 0 pensamento, "por definição subversivo", não acontece no imediato, ele "[...] deve começar por demonstrar as ideias feitas, e deve em seguida demonstrar [...]" (BOURDIEU, 1997, p. 41), o que só pode acontecer a partir de uma "longa cadeia de razões", um processo inaceitável no espaço televisivo. Este, ao contrário, abre espaço para o que o autor chama de fast-thinkers, agentes que se situam entre o campo acadêmico e o jornalísti-

\footnotetext{
${ }^{10}$ Interessante observar que o texto trata de uma TV relacionada à propagação do pensamento intelectual, não fala da TV como um todo. Parece, pelo menos assim o interpreto, que o diálogo busca se dar entre o campo de produção intelectual e uma TV voltada à não ficção.
} 
co, propensos a valorizar o sucesso comercial e suas regras, em detrimento das regras do campo acadêmico, suscetíveis a impor a este último suas próprias legitimidades.

Dessa forma, impõe-se o sucesso comercial, tradicionalmente suspeito, dentro do campo intelectual, como moeda a ser, agora, valorada, transformando o mercado em "instância legítima de legitimação" (BOURDIEU, 1997, p. 37). Ademais, incentiva, dentro dos demais campos, especialmente o jornalístico, aqueles agentes com propensão a simplificar, de forma demagógica, os assuntos postos em relevo.

É nesse cenário que o autor discorre sobre a realização de debates televisivos acerca das questões sociais, em que são envolvidos agentes distintos, com habilidades e propensões bastante diversas, e que são postos frente à frente em uma ilusão de democracia que, na verdade, esconde uma violência simbólica. Para Bourdieu, é necessário tratar diferente a diferença, garantindo aos menos propensos às regras do campo televisivo as mesmas possibilidades discursivas daqueles que ao campo se amoldam:

O que levanta um problema importantíssimo do ponto de vista da democracia: é evidente que nem todos que se servem da palavra são iguais no estúdio. [...] E, para estabelecer um pouquinho de igualdade, seria preciso que o apresentador fosse desigual, isto é, que assistisse os mais desprovidos relativamente, como o fizemos em nosso trabalho de pesquisa La misère du monde. Quando se quer que alguém que não é um profissional da palavra chegue a dizer coisas (e com frequência ele diz então coisas absolutamente extraordinárias, que as pessoas que detêm a palavra o tempo todo nem sequer poderiam pensar), é preciso fazer um trabalho de assistência à palavra. (BOURDIEU, 1997, p. 47).

O jornalismo é visto em sua relação com o campo da televisão. Apesar de ser enquadrado enquanto um microcosmo com leis próprias, que não pode ser explicado apenas pela redução às pressões econômicas, Bourdieu pondera que é necessário observar a relações de forças objetivas dentro do campo jornalístico que, submetido à lógica do polo comercial pela presença da TV como força dominante, exerce, por sua vez, importante influência sobre outros espaços como, por exemplo, o campo político. Nesse contexto, ganham especial relevo as ações dos intelectuais jornalistas e dos jornalistas em si, que ocupam posição dominada no campo dos dominantes, mas com o poder de publicizar, operando sobre o signo da urgência e da renovação constante, muitas vezes atuando para subverter o direito de entrada nos outros campos de produção simbólica. Bourdieu alerta, ainda, para a facilidade com que jornalistas defendem o antiintelectualismo: 
[...] que é uma constante estrutural (muito fácil de compreender) do mundo jornalístico, leva, por exemplo, os jornalistas a levantar periodicamente a questão dos erros dos intelectuais, ou a introduzir debates que não podem mobilizar senão os intelectuais-jornalistas e que muitas vezes não têm outra razão de ser senão permitir a esses intelectuais de televisão existir na mídia, abrindo para si uma vaga. (BOURDIEU, 1997, p. 84).

Dentre as características específicas do campo jornalístico, Bourdieu aponta a capacidade deste de tomar por certo o que está naturalizado, ou seja, de não refletir sobre o que é tido como "óbvio". Essa não reflexão sobre a prática permite que o jornalismo oculte mostrando o que não importa, e que jornalistas usando seus "óculos" - produtos de seus habitus de classe e profissional - mostrem um mundo produzido dentro de um esquema de auto referência profissional que induz a uma "barreira mental" (BOURDIEU, 1997, p. 33), segundo as imposições e disposições de seus habitus, ação que é agravada por uma ideia onipotente sobre o "público" e os "interesses públicos". Um campo, em resumo, que tende a valorizar a urgência em detrimento da reflexão, os temas espetaculares, ou a espetacularização e dramatização dos temas, em detrimento dos temas de difícil discussão.

Um campo que, se levarmos ao pé da letra a crítica do autor, podemos pensar estar fadado a não cumprir com as expectativas que depositamos nele e em sua capacidade de fornecer informações e interpretações dignas e confiáveis para a tomada de posição consciente sobre o mundo. Esta conclusão, no entanto, não pode ser assumida tão linearmente, se lembrarmos que é o próprio Bourdieu que advoga que os campos só podem ser apreendidos relacionalmente. E o autor seria o primeiro a nos desautorizar a generalizar uma análise realizada em momento e campos específicos, na França, há quase duas décadas.

\section{Conclusões finais}

Trabalhar com Bourdieu não é tarefa fácil, dadas as ramificações de seu arcabouço teórico ou a amplitude de seu projeto. Essa dificuldade, no entanto, deve ser enfrentada se quisermos nos apoderar de importantes noções analíticas e de instrumentos de reflexão para os quais sua vasta produção aponta e que continuam extremamente atuais e operativos.

Apesar da propensão em nossas pesquisas do uso das noções de habitus e campo e das referências ao poder simbólico e, muitas vezes da falta de rigor teórico e metodológico com os quais nos apropriamos dessas noções e conceitos, acredito que um dos maiores benefícios, ainda por ser explorado, é o que advém da posição do autor sobre o ofício da pesquisa e o papel do pesquisador. A discussão sobre a reflexividade necessária à pesquisa, a essencia- 
lidade do trabalho coletivo, a liberdade aliada a um apuro rigoroso sobre as técnicas e os métodos, são, não apenas inspiradoras e produtivas, mas, especialmente, fundamentais para consolidar e fortalecer um campo composto por uma série de fragilidades cotidianas e que, algumas vezes, limitam sua capacidade de ocupar espaços nesse loci relacional que é a ciência no Brasil.

\section{Referências}

BOURDIEU, Pierre. Questões de sociologia. Rio de Janeiro: Marco Zero, 1983.

BOURDIEU, Pierre. A Economia das trocas simbólicas. São Paulo: Perspectiva, 1987.

BOURDIEU, Pierre. 0 poder simbólico. Lisboa: Difel, 1989.

BOURDIEU, Pierre. Sobre a televisão. Rio de Janeiro: Jorge Zahar, 1997.

BOURDIEU, Pierre. A miséria do mundo. Petrópolis: Vozes, 1999.

BOURDIEU, Pierre. Autoanálises de um sociólogo. Barcelona: Editorial Anagrama, 2006.

BOURDIEU, Pierre. A distinção: crítica social do julgamento. São Paulo: EDUSP, 2007a.

BOURDIEU, Pierre. Él sentido práctico. Buenos Aires: Siglo XXI, 2007b.

ELBAUM, Jorge; HALPERN, Gerardo. Prolegómenos a Bourdieu: matar dos pájaros de un tiro. Revista Causas y azares, Buenos Aires, n. 7, p. 55-63, invierno 1998.

LAGO, Cláudia. Entre o qualitativo e o quantitativo: a pouca utilização de indicadores e índices na pesquisa em jornalismo. In: Encontro Nacional de Pesquisadores em Jornalismo, 9., 2011, Rio de Janeiro. [Anais eletrônicos...]. Rio de Janeiro: UFRJ, 2011. Disponível em: <http://sbpjor.kamotini.kinghost.net/sbpjor/resumod.php?id=1114>. Acesso em: 10 ago. 2015.

LAGO, Cláudia. Habitus. In: MARCONDES FILHO, Ciro (Org.) Dicionário da Comunicação. São Paulo, Paulus, 2014. p. 217

WACQUANT, Loïq J. D. O legado sociológico de Pierre Bourdieu: duas dimensões e uma nota pessoal. Revista de Sociologia Política, Curitiba, 19, p. 95-110, nov. 2002. 


\title{
Pierre Bourdieu's lessons to the Communication Field
}

\begin{abstract}
This article aims to relate the Pierre Bourdieu's work with the Field of Communication. In order to do that, it begins discussing the genesis of the author's research conceptions, then presents fundamental and recurring concepts in the Communication Field, such as Habitus and Symbolic Power. The article ends by analyzing the appropriation of part of the sociologist work in our field, and defending the importance of this appropriation.
\end{abstract}

\section{Keywords}

Pierre Bourdieu. Communication field. Habitus. Symbolic power.

Recebido em 15/09/2015

Aceito em 03/12/2015 